\title{
The Potential of Renewable Energy in Mozambique: An Overview
}

\author{
Luís Cristóvão ${ }^{1 *}$ Fernando Chichango ${ }^{1} \quad{\text { Pedro Massinga } \mathrm{Jr}^{2} \quad \text { Joaquim Macanguisse }}^{3}$ \\ 1.Faculty of Environmental Engineering and Natural Resources, Zambeze University, Mozambique \\ 2.Faculty of Science, Department of Chemistry, Eduardo Mondlane University, Mozambique \\ 3. National Energy Fund, Mozambique
}

\begin{abstract}
Mozambique is endowed with abundant renewable energy resources, but the country is poor in its capability to exploit and use them. Currently, the country faces many challenges with regard to access and quality of energy and there is serious desertification problem in rural areas. About $67 \%$ of population live and work in rural areas and $80 \%$ of the energy used in the country is in the form of traditional biomass. This leads to serious negative environmental and health impacts. Understanding where the opportunities for tapping this wealth exist and proper technologies for harnessing renewable energy resources is fundamental for economic growth and social development. Thus, this work presents an overview of Mozambique energy situation and the potential of renewable energy resources with focus on four major sources, namely: solar, hydro, wind and biomass. Methodologically, the study uses a comprehensive literature review, several national policy frameworks and statistical data from various official sources. Although the country has enormous potential in renewable energy source, more than $23.000 \mathrm{GW}$, electricity access rate stands at approximately $40 \%$. Also, the country has one of the highest energy costs in Sub-Saharan as proportion of income. In addition, the legislative framework for energy sector is considered to be largely in place, but implementation and enforcement of the regulatory regime appear to lag behind considerably due to lack of financial resources.
\end{abstract}

Keywords: renewable energy, biomass, wind, hydropower, solar, climate change

DOI: $10.7176 / \mathrm{JETP} / 11-2-04$

Publication date:March $31^{\text {st }} 2021$

\section{Introduction}

Mozambique is richly endowed with renewable and non-renewable energy resources. The country has approximately 29.5 million inhabitants, about $67 \%$ live in rural areas - mainly along its $2700 \mathrm{~km}$ coastline - and electricity access rate is estimated at $40 \%$, with urban access rates estimated at $67 \%$ and rural access rates estimated at a mere $27 \%$ (INE, 2018 and Goodrich, 2020). This deficit is evidenced in the ranking of the 20 countries in the world with less access to electricity, of which 13 are from Africa: Nigeria, Ethiopia, Democratic Republic of Congo, Tanzania, Kenya, Uganda, (the former) Sudan, Mozambique, Madagascar, Niger, Malawi, Burkina Faso and Angola (UNEP, 2017). The lack of access to energy is a major factor in the slow progress in attainment of the Sustainable Development Goals (SDGs).

For a country like Mozambique, renewable energy (RE) could help sustainably reduce the energy gaps between the urban and rural areas (SDG 7), while responding to the climate change challenge (SDG 13). The country has substantial RE resources that are fairly distributed throughout the country. These include large hydropower, biomass, wind, geothermal and solar energy. The population rely on traditional forms of biomass to cover basic energy needs, such as firewood, charcoal or dung. Growth of urban and rural areas has placed severe strain on biomass resources, which has led to desertification and deforestation. Additionally, the population projected growth will represent a significant energy and climate challenge for development. It is well known that countries with low electrification rates, have lower GDP per capita and are less developed. Thus, an increase in energy demand in Mozambique, may put pressure in nature and environment.

Hydropower is the dominant source of electricity on the country's main grid extension. As a result of climate change, the country witnessed increasingly unreliable rainfall patterns and more frequent droughts. SpaldingFecher at al. (2017) reported that a change in the water resources availability will result in significant changes in electricity supply. Thus, there are still huge opportunities to include other sources to diversify the energy mix. But, access to electricity via national grids will continue to play a key part in energy access solutions, yet technological advances in RE, especially solar, can dramatically expand alternatives for increasing access to those not served by grids extension. With abundant sun and wind, efforts are being undertaken by the Government to exploit these resources, but judging by the current trajectory of growth, the contribution to the overall supply is still marginal; however, it is expected to increase substantially in the coming years. Due to the aforementioned need to diversify energy mix, in its Strategic Plan 2018-2028, the Mozambique Electric Utility Supplier (EDM) highlighted the need to integrate renewables with national grid and develop commercial off-grid systems for remote areas.

In Mozambique, the technology for harnessing RE resources is still poorly known, the infrastructure for capturing RE sources is scarce, the supply of energy services to design, installation and maintenance of renewable systems is insufficient, and the mechanisms and tools for promoting and regulating technologies are non-existent. 
Thus, development of appropriate technology and regulatory policies, rational use of RE resources and financing schemes could not only check its indispensable needs, but also mitigate some global phenomenon at stake, such as desertification, environmental degradation and greenhouse gas emission. The Government of Mozambique is expected to act to ensure that global SDGs agenda is achieved locally by 2030. Recently, the Government approved an "Integrated Electricity Master Plan 2018-2043" with the purpose of increasing the country's capacity to generate, consume and export electricity. This study, therefore, aims to review the state of RE resources in Mozambique, as well as a review the supporting policies.

\section{Energy Balance}

The SDG 7 aims to ensure reliable, sustainable, modern and affordable access to electricity for all (UN, 2015). In the current formulation, this would require increasing the share of renewable energy in the national energy mix and improvement of energy efficiency. Currently, the power sector in Mozambique is significantly underdeveloped, yet there is huge potential for renewable energy deployment. At $187 \mathrm{GW}$, the country has the largest power generation potential in Southern Africa from untapped coal, hydro, gas, wind and solar resources (USAID, 2020). Visually and quantitatively, the energy in Mozambique can be represented using national energy balance (Figure 1), which shows the primary energy sources, energy supply, conversion, losses and energy being used in 2011.

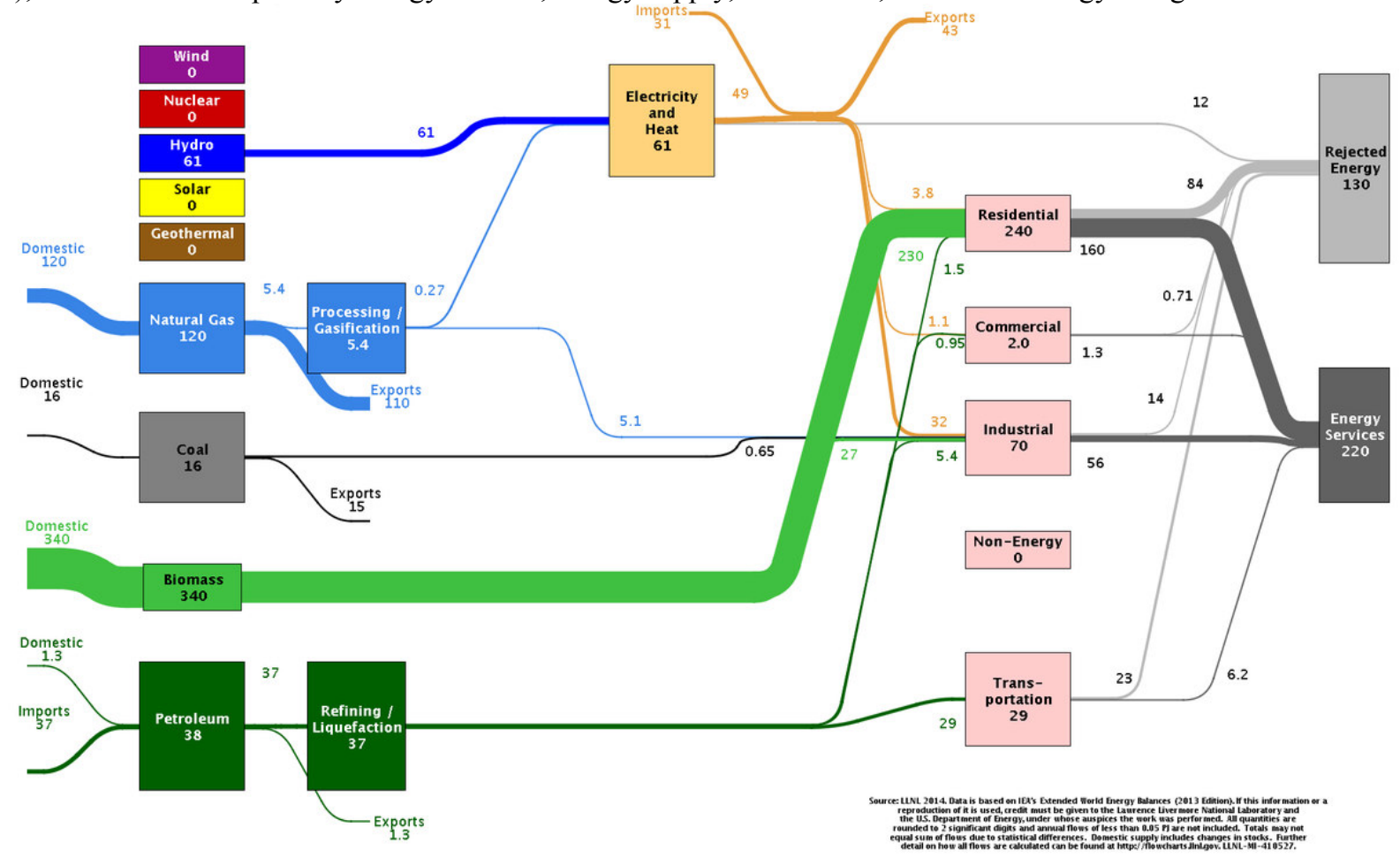

Figure 1. National energy balance. Resource: Laurence Livermore National Laboratory 2014

Such national energy balance illustrates that the country has capacity to generate about 572 PJ from renewable and non-renewables energy. Also, it can be seen that most of Mozambique's primary energy demand in 2011, about 340 PJ generated capacity, has been met by traditional solid biomass (e.g., mainly fuelwood and agricultural waste) for cooking purposes.

Mozambique's power sector consists predominantly of hydropower, with an estimated generating capacity of 61 PJ. The country's electricity is largely utilized for export to neighbouring South Africa and Zimbabwe via the Southern African Power Pool. Paradoxically, HCB-Mozambique exported power (41 PJ) to Eskom-South Africa, which transformed and sold it back (31 PJ) to southern Mozambique at an increased rate.

Projected growth of urban and rural areas will represent a significant energy and climate challenge. The country has been a minor contributor to greenhouse gases emissions, but it is among the countries hardest hit by climate change. Meanwhile, national energy balance shows that solar and wind energy despite significant potential and significant efforts made over the past years to develop them, their potential remains almost entirely untapped. This is due to annual flows less than $0.05 \mathrm{PJ}$, which were not included in the national energy balance. Tapping into these resources would help the country meet the energy challenge, particularly to those underserved by grids in rural areas. Thus, the country has urgent needs to address-access to energy - through a rapid and wide scale expansion of both electricity generating capacity - on-grid and off-grid - and the supply of other forms of energy. 
Although meeting urgent energy needs is priority, it is also important to take into account environmental and climate change concerns (SDG 13). While few countries, including Ethiopia and Kenya, are presently on a trajectory towards universal access to electricity, finding a sustainable way to meet growing energy needs is one of the core development challenges for Mozambique. The combination of rapid developments in technology and decreases in cost increasingly make RE - from small-scale off-grid to large installations - the most cost-effective energy alternative, as reported in the Integrated Electricity Master Plan 2018-2043.

\section{Renewable Energy in Mozambique}

\subsection{Solar Energy}

Mozambique is considerably lagging behind in its goal to achieve universal electricity access by year 2030 . Achieving this goal with on-grid electrification programs alone would be financially costly and unrealistic. With falling technology costs, new business models, and thousands of identified potential sites across Mozambique, offgrid solar power is increasingly a cost-effective option to realize full electrification, especially in rural areas (Baruah and Coleman, 2017). The country consistently presents a high level of solar radiation throughout the territory and throughout the year. The global horizontal irradiation varies between 1785 and $2206 \mathrm{kWh} / \mathrm{m} 2 / \mathrm{year}$. With a global solar potential estimated at 23 TW, the Provinces of Cabo Delgado, Nampula Tete and Niassa have higher levels of Solar radiation. The Province of Tete presents a high annual average of radiation, according to an evaluation in the period between 1990 to 2004, with $1927 \mathrm{kWh} / \mathrm{m} 2 /$ year, very close to the values registered in California (USA) and Kalkbult (South Africa), major world references (Ministry of Energy, 2014).

Although there is an increase in the use of REs in the country, where solar and water sources are the most explored, these are not yet relevant to be counted in the country's energy statistics, as shown in Figure 1. On solar capacity, the country has grown from $1 \mathrm{MW}$ in 2011 to $15 \mathrm{MW}$ in 2017 , but still represents a rather small contribution to the overall supply (Burns M. and Derrick J., 2020). Even so, its contribution has a great impact in solving the problems of access to energy in rural areas and in mitigating environmental risks by using other alternative sources that are more harmful to the environment (Sebastião, 2016).

According to (Mokveld and Eiji, 2018), by 2015, National Energy Fund (FUNAE), an entity dedicated to promoting access to energy in Mozambique from renewable sources, had installed approximately 1500 isolated solar systems, 60 solar systems for water supply and $504 \mathrm{Kw}$ mini-plants for electricity supply. The largest isolated solar plants in the country were installed with financial support from the Government of Koreia, in the Province of Niassa, namely the Mavago (400 MW), Mecula (400 MW) and Muembe (500 MW) power plant.

With a view to improving the quality of energy in the national grid, EDM has been implementing large-scale solar plants. It started with the construction of the Mocuba solar plant (40MW), which is in operation, and the Metoro solar plant whose operation will allow for the improvement of quality of energy in the center / north of the country, from its injection of production into the national grid (ALER, 2017).

The Universal Access Program, that predicts electrification of the entire country by 2030, includes the use of alternative sources, where FUNAE will play a greater role for isolated systems, which may be prepared to be connected to the national grid in the future, in the event of such possibility (Strategic Plan, 2018).

According to the Ministry of Energy (2018), FUNAE has represented in its portfolio 178 development projects, in mini solar grids, totaling the generation of $8.7 \mathrm{MW}$, which allows the connection of 24 thousand families across the country, and 60 locations with potential to install 2 thousand individual systems.

Although incipient, there are already formal private initiatives dedicated to the provision of home solar systems, upon payment of an agreed amount, using the PAYG system, Solar Work and Epilison are at the forefront of the initiative. There is also a need to consider the existence of informal actors dedicated to supplying components for the installation of solar systems, in most cases with equipment from South African, Tanzanian, Chinese markets, or directly obtained in large Mozambican cities, however using illegal commercialization circuits, without payment of tax obligations or guarantees of replacement in case of equipment defect (Greenlights, 2018).

\subsection{Hydropower}

Mozambique's hydropower potential is among the largest in sub-Saharan Africa. The country has 13 major river basins, and there is the potential for both strategic grid expansions via large-scale projects, and smaller-scale developments servicing off-grid population centres (IHA,2020). The energy matrix, the main source of energy for the production of electricity and heat is water, with a small contribution from natural gas. Up to date, hydropower represents $97 \%$ of total primary energy supply in Mozambique. The contribution from other sources is relatively low and almost non-existent. Hydropower is the dominant source of electricity on the country's main grid extension. However, climate variation impacts the use of hydropower and represents big challenges to the water resources sector in Mozambique (Uamusse et al., 2020).

Technically, hydroelectric potential in a given region is generally characterized by the number and extent of existing river basins, the level of average annual precipitation and the high modular flow of rivers. The hydrographic basins that flow to Mozambique have an area of 2.5 million km2 (Ministry of Energy, 2014). The 
most extensive hydrographic basin is that of the Zambezi River with about $1,390,000 \mathrm{~km}^{2}$.

The greatest potential lies in the Zambezi Valley at sites such as Cahora Bassa North and Mphanda Nkuwa. A study carried out by the Ministry of Energy (2014) found that Mozambique has an untapped hydroelectric potential estimated at $18.6 \mathrm{GW}$, of which only roughly $2185 \mathrm{MW}$ have so far been exploited. This energy production is almost exclusively due to the Cahora Bassa Hydroelectric, responsible for about 2075 MW of the total production. There are plans to build more than $5600 \mathrm{MW}$ of new hydropower facilities, most of them in the Zambezi river Valley, Figure 2. Two large scale projects are planned for the short term: Mphanda Nkuwa Dam with $1500 \mathrm{GW}$ and the $1245 \mathrm{MW}$ extension of the Cahora Bassa Dam. However, Simulations of climate impacts indicate gradual reduction of production potential for hydro-electric power plants - both current and proposed - in the Zambezi region where Cahorra Bassa is located (Yamba et al., 2011). The central and northern areas of the country have greater hydroelectric potential, with emphasis on the Provinces of Tete, Manica and Nampula. The rainfall in these areas ranges from $1,000 \mathrm{~mm}$ to $1,400 \mathrm{~mm}$, with greater intensity in the months of December to March.

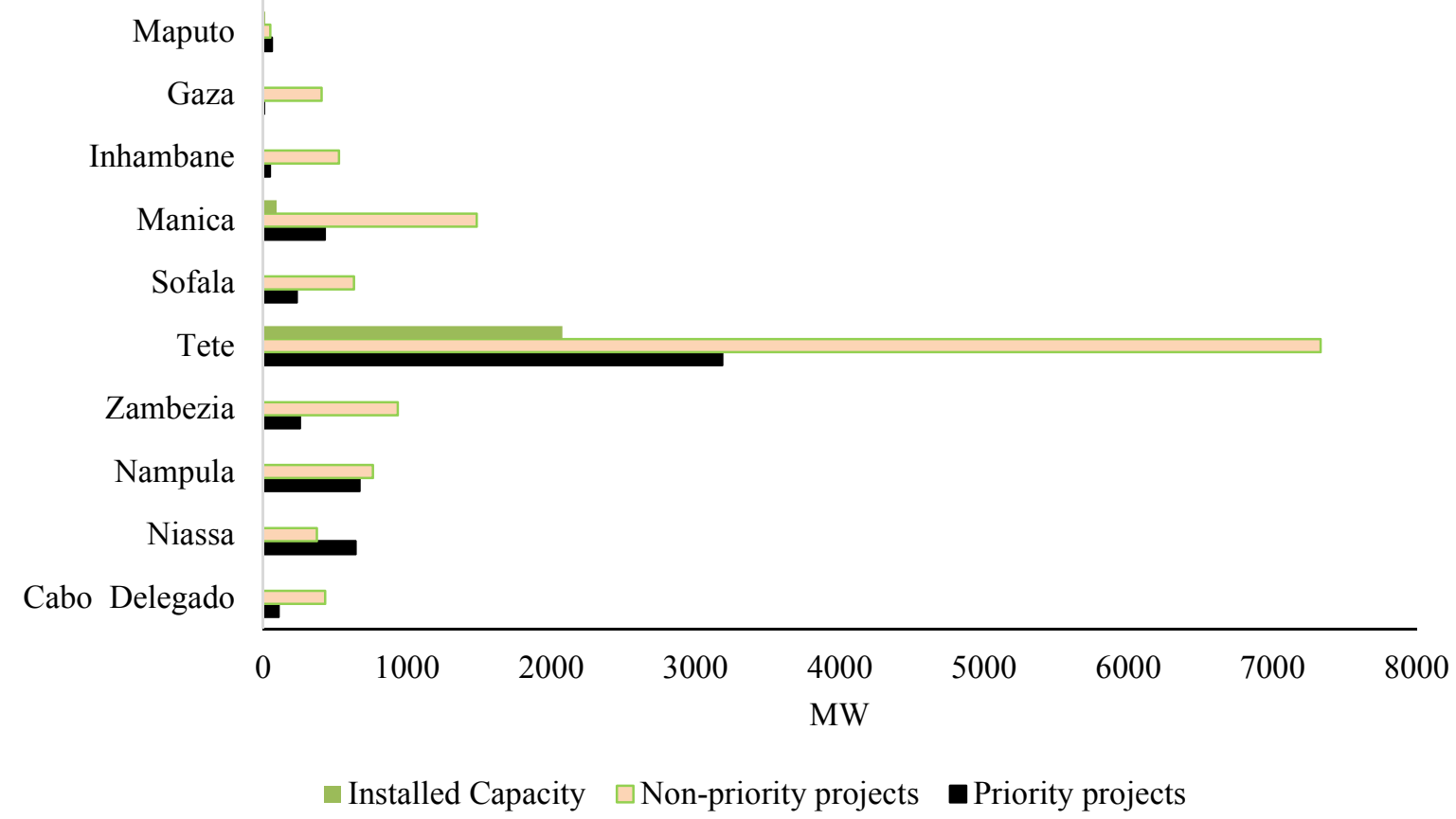

Figure 2. Hydroelectric Power by Province. Source: Adapted from Renewable Energy Atlas of Mozambique (2014)

The hydroelectric potential of new projects existing in Mozambique is estimated in storage capacity of around $107,000 \mathrm{hm} 3$ of water. This storage capacity is twice the Cahora Bassa reservoir. In the country, 351 new projects totaling $5600 \mathrm{MW}$ were identified, most are watercourses (Ministry of Energy, 2014). These plants have great environmental advantages compared to plants with dams. They have minimal environmental damage, such as sedimentation, environmental flows, ecological impact on the fish population and losses due to evaporation.

Hydroelectric generation in the country is around $2.2 \mathrm{GW}$, with a large contribution from the Cahora Bassa hydroelectric, as referred before. However, not all electrical energy produced at Cahora Bassa is injected into the national grid. The power added to the grid depends on the purchase of electricity from Mozambique. Much of this energy is exported to countries like South Africa, Zimbabwe and Malawi. EDM has its own hydropower power station, viz: Corumana, Chicamba, Mavuzi, Cuamba and Lichinga. The hydropower station is responsible for about $114,42 \mathrm{MW}$ of the total production.

\subsection{Wind Energy}

Wind energy is one of the cleanest, sustainable and environmentally-friendly alternative energy sources. It is experiencing increasing development worldwide. The world energy profile published by IRENA - International Renewable Energy Agency, provides an overview of developments in renewable energy in different countries and areas. Such energy profile of the world illustrates renewable energy consumption, electricity capacity and generation, renewable energy policies, renewable resource potential and more. Concerning wind energy in Mozambique, IRENA published that electricity capacity and generation in 2019 was zero (0) MW. The same level of wind energy supply/consumption had also been revealed by Mokveld and Eije (2018), in a Final Energy Report on Mozambique, commissioned by the Netherlands Enterprise Agency, based on Statistics 2015 published by IEA 
- International Energy Agency.

IRENA further compared the country's onshore potential wind power density $\left(\mathrm{W} / \mathrm{m}^{2}\right)$ with that of the world, in seven different classes, measured at a height of 100 meters above ground level (a.g.l.). The distribution of Mozambique's land area in each of these classes compared to the global distribution of wind resources indicated higher wind potential in the first class, $<260 \mathrm{~W} / \mathrm{m}^{2}$. World areas considered to be good wind resources are those in the third class or above, $>420 \mathrm{~W} / \mathrm{m}^{2}$.

Potential wind power density is defined as available wind energy in a flow of air through a unit cross-sectional area normal to the flow. In the previous decade, Hankins (2009) reporting on Mozambique's onshore potential wind power density at a lower height as $20 \mathrm{~m}$ a.g.l., stated that the country has an average wind speed of 6-7 m/s, and displays other favourable conditions for the existence of good wind resource: its location along the southeastern coast of southern Africa, with the second longest coastline in Africa, and some highlands in the interior region consisting of open terrain.

Likewise, in a previous study, Zucule (2012) evaluated the wind energy potential for power generation in Mozambique. The author used the Wind Atlas Analysis and Application Programme (WAsP) model to characterise wind speed patterns and wind frequency distributions at selected meteorological stations. The results of the WAsP model simulations indicated that there is sufficient wind energy resource in both interior and coastal areas, which varies with height. At $10 \mathrm{~m}$ a.g.l., the coastal areas of Ponta de Ouro, Mavelane and Tofinho displayed mean annual wind speed above $5 \mathrm{~m} / \mathrm{s}$. At $50-60 \mathrm{~m}$ a.g.l. the same coastal areas exhibited mean annual wind speed of about 8 $\mathrm{m} / \mathrm{s}$, while the interior area of Lichinga showed a mean annual wind speed of about $6 \mathrm{~m} / \mathrm{s}$.

Between 2011 and 2013, the Government of Mozambique and FUNAE conducted a study that led to the publication of the Renewable Energy Atlas of Mozambique - a key reference document for technical potentials of renewable energy in the country. According to such publication, based on measurements of wind power potential conducted throughout the country, Mozambique is characterized by winds of moderate-low intensity; the average speed is $4-6 \mathrm{~m} / \mathrm{s}$ at $80 \mathrm{~m}$ a.g.l., except in the south of the country (in the province of Inhambane and the northern and coastal regions of Maputo and Gaza) and in the highlands of the Center (in the provinces of Sofala, Zambezia and Tete) and North (in the province of Cabo Delgado) where winds can reach higher speeds of over $7 \mathrm{~m} / \mathrm{s}$. Mozambique has limited wind resources: the wind potential is 4.5 GW (Renewable Energy Atlas of Mozambique, 2014).

\subsection{Biomass}

Biomass is all organic matter of vegetable or animal origin used for the purpose of producing energy. It is one of the oldest forms of energy production known to man. The energy from biomass is used directly for the thermal heating of products or as steam. Steam is also used either directly or for the production of other forms of energy such as electrical energy.

Mozambique holds extensive biomass resources, with about $50 \%$ of the country under forest cover. Biomass energy accounts for about $80 \%$ of the total energy consumed. A large percentage of this energy is for residential use and another portion is used in industry for the production of electrical energy through the cogeneration process. The predominance of biomass for the production of electricity in Mozambique is in forest resources, biomass from industrial and agro-industrial residues, industrial process residues (paper industry, sugar industry), urban solid residues and biogas. The widespread and inefficient use of traditional biomass lead to overexploitation of the forest, environmental degradation, problems to end-users and high $\mathrm{CO} 2$ emissions.

The potential of woody biomass for electricity production in Mozambique is estimated at more than $2 \mathrm{GW}$ (Ministry of Energy, 2014). This resource was obtained considering a combination of the forest aggregate existing in a given area, with the potential for planting sugar in also given areas. Figure 3 illustrates the potential biomass for generation of electricity.

\section{Potential of biomass for electricity (MW)}

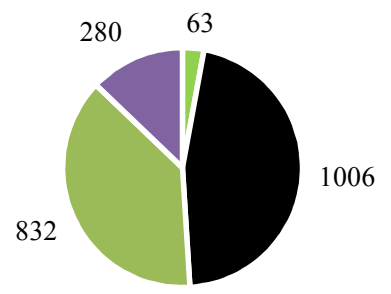

$$
\begin{aligned}
& \text { - Municipality solid waste } \\
& \text { - Residual Forest biomass for } \\
& \text { agroindustrial waste } \\
& \text { - Bagasse in sugar industry } \\
& \text { - Pulp in paper industry }
\end{aligned}
$$

Figure 3. Potential biomass projects for the production of electricity

Resource: Adapted from Mozambique's Renewable Energy Atlas ( Ministry of Energy, 2015)

The potential of biomass in Mozambique is not uniformly distributed. For residual forest biomass, the 
provinces with favorable conditions are Zambezia and Niassa. These have high levels of precipitation and better weather conditions. For cogeneration raw material, the case of residues from industrial processes such as sugarcane bagasse, and pulp in paper industry, these resources occur in the delta of the Zambezi River and in the delta of the Limpopo River.

In addition to the estimated biomass for the production of electricity, the country also has great unrecognized biomass potential for the production of biofuels. There are agro - ecological conditions, availability of land and geographic location of the country which is favorable. Some resources mentioned by the Ministry of Energy (2014) include the production of biodiesel from Jatropha curcas Linn and Coconuts. For the production of Ethanol, the resources are sugar cane, sorghum, cassava and micro algae.

\section{National Energy Policy framework, Laws and Regulations}

Globally, RE development needs strong governmental policies. In Mozambique, energy legal framework is composed of a variety of policies, strategies and regulations. The country policy recognizes that adequate access to energy is critical for social and economic development of the country, yet the country faces many challenges in fulfilling global commitment, such as SDG 7 (energy and its universal access) and SDG 13 (Climate change). Access to electricity is ranked amongst the lowest in Africa. Moreover, even when energy is available, it is expensive and unreliable.

In Mozambique, the challenge has been to determine what regulatory frameworks and incentives schemes are necessary to implement a wide scale expansion of electricity generating capacity, both on-grid and off-grid renewable energy to ensure that the country receives the most benefit from the exploitation of its natural resources. Furthermore, it is important that the exploration and exploitation of natural resources are undertaken in compliance with the sustainable socio-economic and environmental development strategy. Thus, several major laws, legislations, strategies and policies in the power sector were developed, such as: Law of Electricity Act No21/97 of 1 October 1997 amended by Law 15/2011 of 10 August, creation of FUNAE (Decree 24/97 of 22 July 1997), Energy Policy 1998, Energy Strategy 2009 (Resolution 10/2009) replaces the former Energy Strategy (approved by Resolution 24/2000, of October), New and Renewable Energy Development Policy (2009), New and Renewable Energy Strategy for the 2011-2015 period (2011), The biofuels Policy Strategy 2009 (Resolution 22/2009), Renewable Energy Strategy 2011-2025, The Strategy of the conversation and sustainable use of biomass energy (2013), The National Energy Strategy (2014-2023), creation of Feed-in-tariff for Renewable Energy (Decree 58/2014 of 17 October), creation of MIREME (Decree 1/2015, of 16 January), creation of ARENE (Law 11/2017 of 8 September), EDM Strategic Plan 2018-2028 and Integrated Electricity Master Plan 2018-2043.

The Government plans to expand access of electricity to the universe of the Mozambican people until 2030. It is lagging behind to achieve this goal. Although the country has a diversity of natural resources available for power generation, it is necessary to develop attractive policies to bring more players into the process of exploration and connection of energy to local communities (Baruah \& Coleman, 2017).

The Mozambican electrification sector still presents challenges that hinder its sustainability: lack of human resources, lack of financial capacity, great dispersion among the populations and long distances to the production centers. The biggest challenge to change the current situation is the establishment of clear policies for the inclusion of the private sector, which is why it is necessary to implement technologies adequate for each type of region, highlighting the use of renewable energies in more isolated regions from the national network (ALER,2017).

In order to materialize the electrification process, it is foreseen an allocation of funds for an electrification account to be created from state resources. Such account will consist of $3 \%$ of the electricity invoice sold to customers not included in the social tariff, contributions from large consumers and revenues from concessions for the generation of electricity (Strategic Plan, 2018).

Within the scope of the national electrification strategy, which provides for various energy solutions in the country, four main players are indicated, where the Ministry of Mineral Resources and Energy (MIRENE) appears as the main coordinator, the energy regulatory authority (ARENE), EDM and FUNAE, acting directly in the implementation process, seeking greater involvement of the private sector (Strategic Plan 2018). Despite the great potential for exploitation of RE, current energy market policies are a major barrier to private sector penetration, especially in rural areas (IRENA, 2020).

There are a number of benefits that are offered to players in the energy sector, including the reduction of tax rates. However, these benefits are reserved for companies operating in connection with the national network, not being observed in the same way in renewable energies sector (IRENA, 2020).

In order to guarantee a greater gain in the main electrification processes until 2030, with the best possible economic management, the government will establish mechanisms to make the implementation and monitoring processes clearer. In the case of areas for the grid, where often the activities of electrification are aimed at social purposes, FUNAE was tasked with building infrastructure, where funds are not subject to reimbursement, and mobilization will be done via electricity bills. For projects above $1 \mathrm{MW}$, under the responsibility of FUNAE, the possibility of being connected to the national grid in the future should be considered (Strategic Plan 2018). 


\section{Conclusion}

It is clear that Mozambique is endowed with abundant, high quality renewable energy resources, but still has low rate of electricity consumption per capita, about $443 \mathrm{kWh}$. This is directly linked to the level of poverty in the country. Although the performance of energy sector is perceived as being below expectation, a number of energy policies have been developed, but the implementation has been limited by combination of factors that include: lack of skilled manpower, weak dissemination strategies, pricing distortions that places RE at disadvantage and poor infrastructure. With lack of grid infrastructure and high energy cost, domestic consumption is highly dependent on Biomass. But, growth of urban and rural areas has put huge pressure in nature and environment. Moreover, a major proportion of Mozambique energy currently comes from RE resources, primarily from unreliable hydropower. Due to its geographical location, the country is extremely vulnerable and exposed to the impacts of climate variability. Thus, future changes in climate could negatively affect the performance of hydropower plants and the economy, since significant amount of energy is exported to neighboring countries. Therefore, there are still huge opportunities to include other sources to diversify the energy mix. The energy balance shows that wind and solar energy have insignificant contribution to the energy supply. Tapping into these resources would help the country meet the energy challenge, particularly to those underserved by grids in rural areas. As such, future development efforts must fit into the larger energy-population-climate nexus of global sustainability.

\section{Acknowledgements}

The authors express their gratitude to the Austrian Development Cooperation - APPEAR for providing financial support through the Capacity Building for Renewable Energy Technologies in Mozambique project.

\section{Reference}

1. ALER. (2017). Energias Renováveis em Moçambique- Relatório Nacional de Ponto de situação/outubro2017. (2. ${ }^{\mathrm{a} e d .) . ~ M a p u t o .}$

2. Baruah, P., \& Coleman, B. (2017). Off Grid Solar Power in Mozambique: opportunities for universal energy access and barriers to private sector participation. Seoul Estratégia nacional de Electrificação 2018-2030. (2018). Maputo.

3. EDM. (2018). EDM Strategic Plan 2018-2028. (2018). Electrificação de Moçambique, Mozambique.

4. EDM. Integrated Electricity Master Plan 2018-2043. (2018). (2018). Electrificação de Moçambique, Mozambique.

5. Goodrich, G. (2020). Mozambique: A Regional Electricity Exporter. Available online: https: africaoilandpower.com .

6. Greenlights. (2018). Off- Grid Solar Market Assessment in Mozambique. London

7. Hankins, M. (2009). A Renewable Energy Plan for Mozambique. Justiça Ambiental, Maputo, Moçambique, 7-60.

8. Instituto Nacional de Estatística (INE). (2018). Estatística de Violência Domestica 2017. Maputo, Mozambique.

9. International Hydropower Association. (2020). Available online: https: hydropower.org/countryprofiles/mozambique on 20 January 2021.

10. International Renewable Energy Agency-IRENA. (2020). Energy Profile Mozambique. online https://www.irena.org/IRENADocuments/Statistical_Profiles/Africa/Mozambique_Africa_RE_SP.pdfon 26 December 2020.

11. Ministry of Energy. (2014). Renewable Energy Atlas of Mozambique - Resources and Projects for Power Generation. Maputo, Moçambique. p128.

12. Mokveld, K., \& Eije, E.V. (2018). Final Energy Report Mozambique. p43.

13. Sebastião, A.P. (2016), O Modelo de Electrificação de Moçambique: A importância para o Desenvolvimento. International Business and Economic Review. N 200.doi:https://recil.grupolusofana.pt/handle/10437/8028.

14. Spalding-Fecher, R.; Joyce, B.; \& Winkler, H. (2017). Climate Change and Hydropower in the Southern African Power Pool and Zambezi River Basin: System-Wide impacts and policy implications. Energy Policy 103, 84-97.

15. Uamusse, M.; Tussupova, K.; \& Persson, K. (2020). Climate Change Effects on Hydropower in Mozambique. Applied Science, 10. 4842; doi:10.3390/app10144842.

16. UN. Transforming our world: the 2030 Agenda for Sustainable Development. Available online: https://www.sdgs.un.org/2030agenda (accessed on 8 january 2021).

17. UNEP. (2017). Atlas of Africa Energy Resources. Kenya: UNEP.

18. USAID. (2020). Mozambique Power Africa Fact Sheet. Retrieved at https://www.usaid.gov on 8 January 2021.

19. Yamba F., Walimwipi H., Jain S., Zhou P., Cuamba B., \& Mzezewa C. (2011). Climate change/variability 
implications on hydroelectricity generation in the Zambezi River Basin, Mitigation and Adaptation Strategy for Global Climate Change, 16: 617-628.

20. Zucule, J. (2012). An Evaluation of Wind Energy Potential for Power Generation in Mozambique. University of KwaZulu-Natal, Durban, South Africa, p184. 